\title{
PEMBUATAN BIOETANOL DENGAN TEKNIK DESTILASI REFLUKS SATU KOLOM
}

\author{
Yansen Sumampouw $^{1)}$, Hesky S. Kolibu ${ }^{1)}$, Seni H.J. Tongkukut ${ }^{1)}$ \\ ${ }^{1)}$ Program Studi Fisika FMIPA UNSRAT Manado \\ e-mail: jansensumampouw@gmail.com; heskystevy@yahoo.com; linashafi@yahoo.com
}

\begin{abstract}
ABSTRAK
Produksi minuman arak cap tikus di Propinsi Sulawesi Utara sangat melimpah dan dapat mencapai 100.000 liter per hari. Penggunaannya sebagai minuman keras telah menyebabkan berbagai tindak kejahatan yang terjadi dalam masyarakat sehingga diperlukan usaha untuk mengalihkan pemanfaatannya dari minuman keras menjadi etanol konsentrasi tinggi yang kemudian dapat diproses menjadi campuran bahan bakar yang disebut gasohol. Bioetanol yang dapat digunakan sebagai bahan campuran bahan bakar harus memiliki tingkat kemurnian $96 \%$. Alkohol 40\% akan ditingkatkan kemurniannya menjadi $96 \%$. Penelitian ini dilakukan dengan metode eksperimen menggunakan alat pembuat etanol dengan teknik destilasi refluks. Pengukuran dilakukan secara terpisah untuk masing-masing variasi suhu. Hasil optimal yang diperoleh dalam penelitian ini yaitu ketika suhu boiler berada pada rentang suhu $75,2^{\circ} \mathrm{C}-75,4^{\circ} \mathrm{C}$ dengan tingkat kemurnian etanol mencapai 96\% - 96,5\%.
\end{abstract}

Kata Kunci : Cap Tikus, Bioetanol, Destilasi Refluks.

\section{BIOETHANOL DEVELOPING WITH ONE COLUMN REFLUX DISTILLATION TECHNIQUE}

\begin{abstract}
ABSTACT
Wine beverage (local name :Cap Tikus) production in North Sulawesi is very abundant and can reach 100,000 liters per day. Its use as a liquor has caused a variety of crimes that occur in society so that needs necessary effort to divert the utilization of liquor into a high concentration of ethanol that can be processed into fuel mixture called gasohol. Bioethanol can be used as a fuel mixture should have a purity level of $96 \%$. In this research Alcohol $40 \%$ will be increased to $96 \%$ purity. This research was conducted by an experimental method using ethanol maker with reflux distillation technique. Measurements performed separately for each variation in temperature. Optimal result obtained in this research are when the boiler temperature is at a temperature range of $75.2{ }^{\circ} \mathrm{C}-75.4{ }^{\circ} \mathrm{C}$ with a purity level of ethanol reached $96 \%-96.5 \%$.
\end{abstract}

Keywords : Cap Tikus, Bioethanol, Reflux Distillation Technique.

\section{PENDAHULUAN}

Bahan bakar minyak (BBM) adalah sumber energi tak terbarukan dan diprediksi akan habis sekitar tahun 2040 (Laisnima, 2006). Pada tahun 2005 pemakaian energi di Indonesia mencapai 68,9 juta ton BBM, dengan rincian 57,9\% dari minyak, 35,1\% gas alam, serta $7 \%$ batubara dan hidro energi (Badan pusat statistik). Keadaan tersebut di atas menyebabkan manusia berupaya untuk menemukan sumber bahan bakar pengganti minyak sebagai sumber energi alternatif. Beberapa sumber energi yang dapat digunakan sebagai pengganti minyak adalah gas, matahari, nuklir, air, batu bara, produk tanaman, dan angin. Salah satu sumber bahan bakar alternatif dari nabati (tumbuhan) yang cukup potensial sebagai sumber energi adalah bioetanol.

Pada dasarnya bioetanol dapat diproduksi dari tanaman yang banyak tumbuh di Sulawesi Utara seperti pohon aren, jagung, padi dan berbagai umbi - umbian yang banyak mengandung karbohidrat. Bahan mentah pembuatan bio etanol tersedia melimpah khususnya di Sulawesi Utara dan Indonesia pada umumnya, sehingga bioetanol dapat membantu mengurangi ketergantungan 
Indonesia bahkan dunia pada bahan bakar minyak.

Produksi minuman arak dengan kadar alcohol hingga $40 \%$ sangat melimpah di provinsi Sulaweai Utara dan diperkirakan mencapai 100.000 Liter (Sangian, 2007). Penggunaannya sebagai minuman keras telah menyebabkan berbagai tindak kejahatan yang terjadi dalam masyarakat sehingga diperlukan usaha untuk mengalihkan pemanfaatannya dari minuman keras menjadi etanol konsentrasi tinggi yang kemudian dapat diproses menjadi campuran bahan bakar yang disebut gasohol.

Salah satu metode untuk membuat etanol adalah dengan menggunakan teknik destilasi refluks. Alat destilasi refluks merupakan salah satu alat pembuat etanol yang dapat menghasilkan bioetanol (Sangian, 2006). Bioetanol sangat dibutuhkan sebagai pengganti Bahan bakar minyak. Hal ini yang mendorong peneliti untuk membuat bioetanol dengan kemurnian $96 \%$.

\section{Rumusan Masalah}

Teknik pemurnian etanol di Sulawesi Urata masih menggunakan cara tradisonal dan analisis tentang kemurnian etanol di Sulawesi Utara masih sangat terbatas. Selain itu teknik destilasi menggunakan teknik refluks yang dapat menghasilkan etanol dengan kemurnian $96 \%$ belum banyak dikenal.

\section{Batasan Masalah}

Penelitian ini dibatasi pada pemurnian minuman arak Cap Tikus dengan kadar alcohol $40 \%$ menjadi bioethanol industry grade dengan kemurnian $96 \%$.

\section{Tujuan Penelitian}

Penelitian ini bertujuan untuk menghasilkan bio etanol industry grade dengan kemurnian 96\%. Sekaligus untuk memperkenalkan teknik destilasi refluks bagi masyarakat di Sulawesi Utara.

\section{Etanol}

Etanol (ethil alcohol, grain alkohol) merupakan sekelompok senyawa kimia yang molekul-molekulnya mengandung gugus hydroxyl atau $-\mathrm{OH}$ dan terikat pada atom karbon dengan rumus molekul $\mathrm{CH}_{3} \mathrm{CH}_{2} \mathrm{OH}$ (Salomons dan Graham, 2007). Sifat-sifat fisik dari etanol adalah sebagai berikut : etanol mencair pada suhu $-114,1^{\circ} \mathrm{C}$ dan mendidih pada suhu $78,4^{\circ} \mathrm{C}$, serta mempunyai massa jenis $0,789 \mathrm{~g} / \mathrm{ml}$ pada suhu $20^{\circ} \mathrm{C}$ (White, 1988).<smiles>CO</smiles>

Gambar 1. Rumus Bangun Etanol

Nama umum untuk alkohol diturunkan dari gugus alkol yang melekat pada $-\mathrm{OH}$ dan kemudian ditambahkan kata alkohol. Dalam sistem IUPAC, akhiran -ol menunjukkan adanya gugus hidroksil. Alkohol digolongkan ke dalam primer $\left(1^{\circ}\right)$, sekunder $\left(2^{\circ}\right)$, atau tersier $\left(3^{\circ}\right)$.

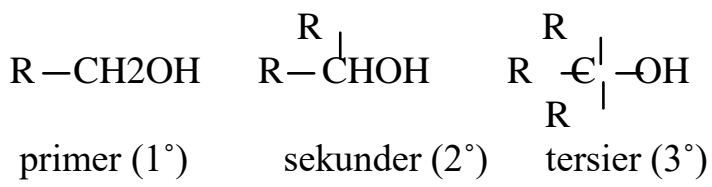

\section{Destilasi}

Destilasi adalah operasi pemisahan komponen-komponen cair dari suatu campuran fase cair, khususnya yang mempunyai perbedaan titik didih dan tekanan uap yang cukup besar. Perbedaan tekanan uap tersebut akan menyababkan fase cairnya mempunyai komposisi yang perbedaannya cukup signifikan. Fase uap menggandung lebih banyak komponen yang memiliki tekanan uap rendah, sedangkan fase cair lebih banyak menggandung komponen yang memiliki tekanan uap tinggi (Sudjadi, 1989).

Jenis-jenis destilasi yang sudah digunakan secara umum adalah:

1. Destilasi Sederhana,

2. Destilasi Bertingkat

3. Destilasi Azeotrop

4. Destilasi Kering

5. Destilasi Vakum

6. Destilasi Uap

\section{Destilasi Refluks}

Teknik destilasi refluks sebenarnya hampir sama dengan destilasi sederhana, yang berbeda terletak pada proses kondensasi yang terjadi secara berulang - ulang (Sangian, 2007). 


\section{METODE PENELITIAN \\ Lokasi dan Waktu}

Penelitian ini dilakukan dengan cara eksperimen yang dilaksanakan pada bulan Juli sampai Sebtember 2009 di Laboratorium Energi Terbarukan Jurusan Fisika Universitas Sam Ratulangi Manado

\section{Alat dan Bahan}

Alat yang digunakan dalam penelitian ini adalah, 1 unit alat destilasi refluks satu kolom 1,75, 1 unit kompor minyak tanah, Termometer Digital LH 666 198, Boiler $12 \mathrm{~L}$, pompa air LH 579 (8...20V), power supply LH 59109, Sirkulator air elekotronik HAAKE L Fissons DIN 12879 Klasse 1W, Alcohol meter, Gelas ukur silinder.

Bahan yang digunakan dalam penelitian ini adalah, Alkohol konsentrasi 40\% hasil Produksi Masyarakat, Air, Minyak tanah.

\section{Desain dan Konstruksi Eksperimen}

Peralatan destilasi refluks didesain dan dikonstruksi terdiri dari kolom destilator, boiler, kondensor, inlet air dingin (2 buah), outlet air hangat (2 buah), termometer digital ( 2 buah), sirkulator air elektronik (1 buah), kompor minyak tanah (1 buah), ratusan packing materials dan pompa air (2 buah). Adapun dimensi dari peralatan destilator yang dibuat adalah: panjang kolom $135 \mathrm{~cm}$, diameter kolom 1,75", panjang kondensor $125 \mathrm{~cm}$, dan volum boiler 12L. Adapun spesifikasi peralatan pendukung adalah termometer digital LH 666198 termokopel $\mathrm{NiCr}-\mathrm{Ni} \quad\left(-50(+1200)^{\circ} \mathrm{C}\right), \quad$ sirkulator air elekotronik HAAKE L Fissons DIN 12879 Klasse 1W, pompa air LG|H 57922 (8...20V), power supply LH 59109, packing material dari karbon aktif dan kompor minyak tanah, HOOK 16 sumbu.

Masing-masing komponen di atas memiliki fungsi yaitu : Alat destilasi refluks kolom, sebagai alat yang digunakan untuk mendestilasi alkohol $40 \%$ produksi masyarakat menjadi etanol. Kompor minyak tanah merek HOOK, sebagai alat pemanas, Termometer digital LH 666 198, sebagai alat pengukur suhu, Boiler, sebagai tempat penampung Bahan Baku alkohol 40\% yang akan di panaskan, Pompa air, sebagai alat untuk menyalurkan air ke alat destilasi refluks, Sirkulator air elekotronik, tempat air mengalir untuk menurunkan suhu pada kondensor, Alkohol meter, alat untuk mengukur kemurnian etanol, Gelas ukur silinder, tempat etanol yang akan di ukur kemurniannya

\section{Proses Pembuatan}

Bahan mentah yang digunakan dalam penelitian ini adalah alkohol $40 \%$ dari aren, alkohol ini telah didistilasi satu tahap oleh peteni dari air nira dengan menggunakan peralatan tradisional. Peralatan tradisional ini merupakan alat destilasi yang sengat sederhana sehingga hanya dapat menghasilkan beer yang berkonsentrasi 20 sampai $40 \%$.

Beer ini digunakan sebagai bahan pembuatan bioetanol. Boiler dengan ukuran 12 liter diisi dengan $3 / 4$ cairan alkohol produksi masyarakat, kemudian boiler dihubungkan dengan alat destilasi refluks dan di usahakan boiler tidak lebih tinggi dari dari alat destilasi refluks. Apabila terjadi peningkatan suhu yang melebihi titik didih dari etanol, maka temperatur akan di netralkan dengan menggunakan pompa air yang telah di hubungkan dengan alat destilasi refluks sehingga keadaan kesetimbangan akan tercapai.

Dan pada akhirnya uap etanol dan sejumlah kecil uap air yang masuk kedalam alat destilasi refluks akan mengalami proses kondensasi kemudian keluar menjadi bio etanol dengan konsentrasi $96 \%$. Bio etanol akan ditampung pada penempung yang telah dihubungkan dengan rubber fitting (karet pengencang) untuk nenghindari kondensasi air dari udara. 


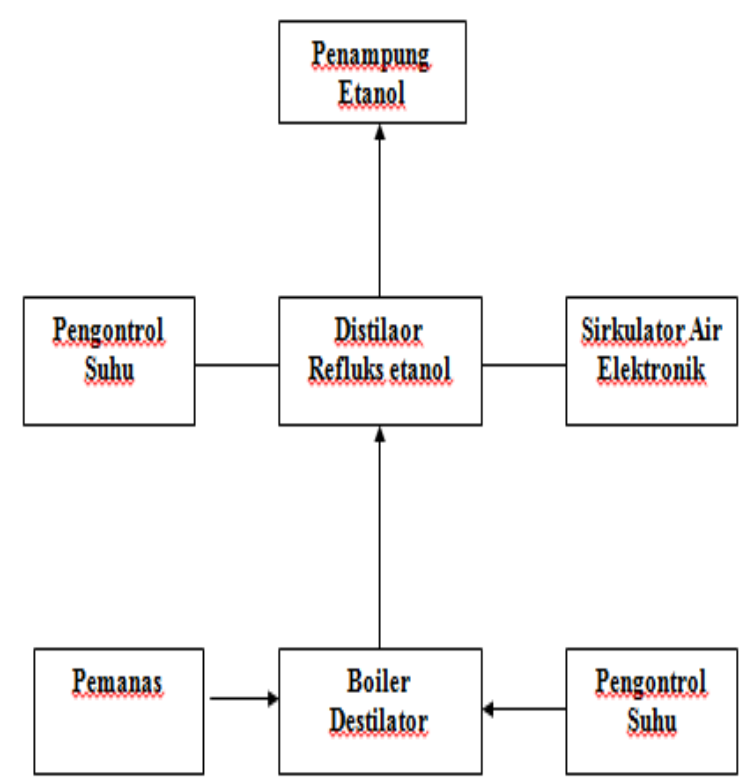

Gambar 2. Diagram proses pembuatan bioethanol dengan teknik refluks.

\section{Diagram Alir Penelitian}

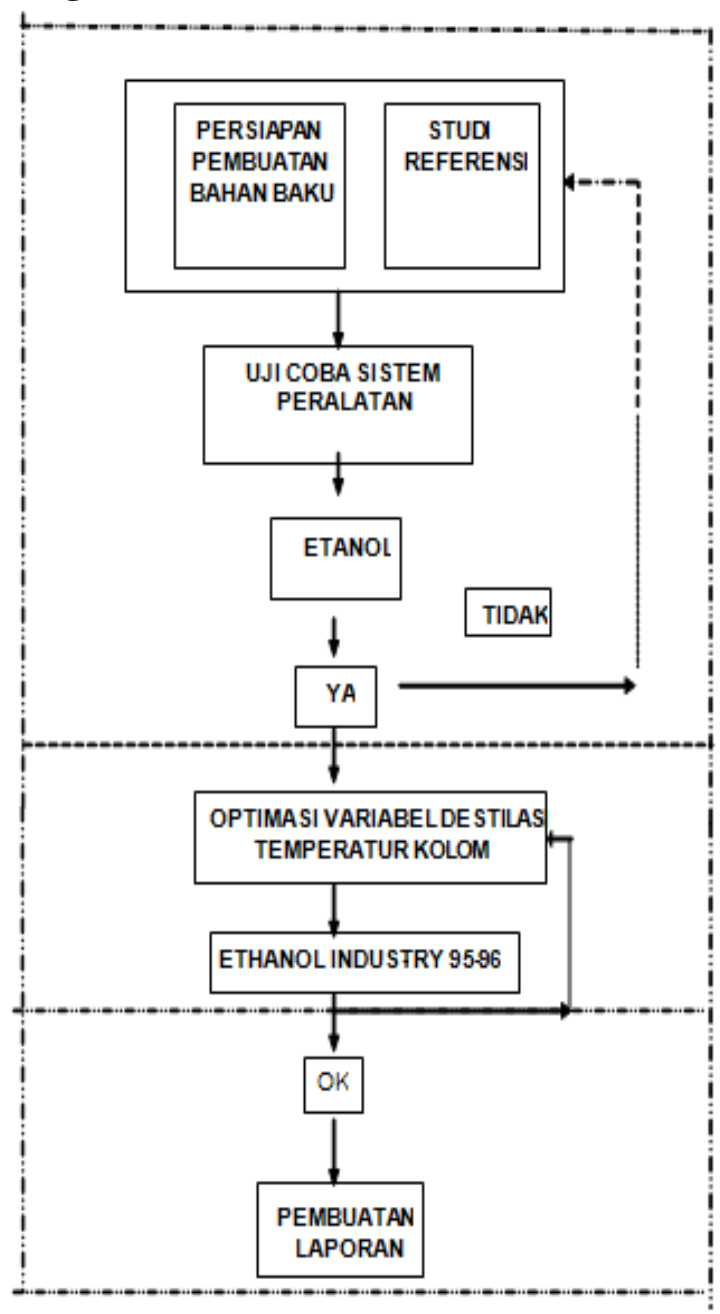

Gambar 3. Diagram alir penelitian

\section{HASIL DAN PEMBAHASAN}

Dengan menggunakan alat destilasi refluks satu kolom telah dilakukan eksperimen pembuatan bio etanol serta pegukuran tingkat kemurnian yang diperoleh dari beberapa temperatur yang berbeda dengan menggunakan alat ukur etanol meter. Pengukuran kemurnian dilakukan secara terpisah untuk masing-masing percobaan dengan menjaga suhu boiler secara manual. Data yang diperoleh disajikan dalam tabel berikut.

Tabel 1. Tingkat kemurnian terhadap suhu kolom

\begin{tabular}{|l|l|l|}
\hline No & Suhu kolom & Kemurnian \\
\hline 1 & $76,5-77^{\circ} \mathrm{C}$ & $93 \%$ \\
\hline 2 & $76-76,5^{\circ} \mathrm{C}$ & $94 \%$ \\
\hline 3 & $75,4-75,6^{\circ} \mathrm{C}$ & $95 \%$ \\
\hline 4 & $75,4^{\circ} \mathrm{C}$ & $96 \%$ \\
\hline 5 & $75,2^{\circ} \mathrm{C}$ & $96,5 \%$ \\
\hline
\end{tabular}

Pada tabel di atas, terlihat pengukuran tingkat kemurnian etanol dimulai dari suhu $75,2^{\circ} \mathrm{C}$ disebabkan etanol yang diperoleh dari proses kondensasi baru mulai mengalir pada suhu tersebut. Kemudian secara eksperimen terlihat bahwa semakin bertambah suhu, semakin berkurang tingkat kemurnian dari etanol. Hal ini disebabkan karena air yang terkandung di dalam beer yang digunakan sebagai bahan untuk eksperimen semakin banyak yang menguap bersamaan dengan etanol. Dengan demikian terlihat suatu hubungan langsung yang cukup jelas, yaitu semakin berkurang kemurnian etanol berarti semakin banyak air yang terkandung di dalamnya.

\section{KESIMPULAN DAN SARAN \\ Kesimpulan}

1. Telah berhasil dilakuakn pembuatan bioethanol industry grade dengan tingkat kemurnian mencapai $96 \%$ - 96,5\% dengan teknik destilasi refluks.

2. Hasil optimal yang diperoleh dalam penelitian ini yaitu ketika suhu boiler berada pada rentang suhu $75,2^{\circ} \mathrm{C}-75,4^{\circ} \mathrm{C}$ dengan tingkat kemurnian etanol mencapai 96\% - 96,5\%. 


\section{Saran}

Perlu dilakukan riset lebih lanjut dari penelitian ini untuk mendapatkan etanol dengan kemurnian 99,9\%

\section{DAFTAR PUSTAKA}

Atkins, P.W. 1997. Kimia Fisika. Penerbit Erlangga. Jakarta.

Brice, R. 2006. Energy Secretary Promotes President Bush's Energy Inisiative. [online].http://www.siliconinvestor.co $\mathrm{m} /$ readmsgs.aspx ?subjectid $=55246 \& \mathrm{~m}$ sgnum $=795 \&$ batchsize $=10 \&$ batchtype $=\mathrm{Next}$

Laisnima. 2006. Melirik Etanol Sebagai Bahan Bakar.

Masyithat, Z., B. Haryanto. 2006. Perpindahan Panas. Medan. Departemen Teknik Kimia. Universitas Sumatra Utara.

Sangian, H. F. 2007. 'Cap Tikus' Bisa Gantikan Bensin. [online]. http://finance.detik.com/read/2007/07 /31/123143/811457/4/cap-tikus-bisagantikan-bensin

Sangian, H. F. 2006. Air Nira Bisa Jadi Alternatif BBM.[online]. http://www.fisikanet.lipi.go.id/utama.c gi?cetakartikel\&1170378413

Salomons dan Graham. 2007. Organic Chemistry. Wiley. New York

Sudjadi, 1989. Kimia Analisis : Metode Pemisahan. Yogyakarta. Kanisius

Schmidt, 1949. Thermodynamics. Oxford at the Claredon Press

White, D.H.Jr., Practical Aspects Of Air Purification by Pressure Swing Adsorption. AIChE Symp. Series, 84, n.264,pp.129-132 (1988) 